\title{
MATERNAL AND FOETAL OUTCOME IN SEVERE PREECLAMPSIA AND ECLAMPSIA IN A TERTIARY CARE RURAL HOSPITAL, KARNATAKA, INDIA.
}

\section{Obstetrics \& Gynecology}

Ravindra S Pukale Professor and HOD, Department of OBG, Adichunchanagiri Institute of Medical Sciences, Karnataka, India.

\section{ABSTRACT}

INTRODUCTION: Preeclampsia and eclampsia are a multisystem disorder occurring during pregnancy, complicating 3-8\% of pregnancies accounting $10-15 \%$ of maternal and neonatal mortality and morbidity.

AIMS AND OBJECTIVES: The aim is to study severe preeclampsia and eclampsia and associated maternal and foetal outcomes at a rural tertiary health care centre.

MATERIALS AND METHODS: This is a prospective cohort study conducted at Sri Adichunchanagiri Institute of Health Sciences and Research Centre, B.G Nagara, Karnataka from July 2018 to December 2019. Patients included in the study will be as per inclusion and exclusion criteria. Patients with severe preeclampsia and eclampsia will be included by thorough history taking and data will be entered in Microsoft Excel and outcomes will be analysed using Epi Info software.

RESULTS: Out of 3068 deliveries conducted, 157 cases were diagnosed with severe preeclampsia and eclampsia. Incidence of severe preeclampsia being $4.7 \%(\mathrm{n}=146)$, and that of eclampsia $(\mathrm{n}=11,0.3 \%)$. Majority belonged to age group $21-25$ years $(47.1 \%), 90(57.3 \%)$ were Primigravida. Preterm deliveries before 32 weeks accounted $21.6 \%(n=34)$, while before 34 weeks were $29.9 \%(n=47)$. A total of $29.4 \%$ preterm deliveries $(n=109)$ were observed. Onset of eclampsia was noted mostly in antepartum period accounting $54.54 \%(n=6)$ of total eclampsia case report, $47.13 \%(\mathrm{n}=74)$ were started on Pritchard's regimen. Caesarean section was undertaken in $36.9 \%(\mathrm{n}=58)$ patients with IUGR being common indication ( $\mathrm{n}=19,32.7 \%$ ). IUD was noted in $7.6 \%$, LBW in $75.15 \%$

CONCLUSION: The importance of continued efforts in monitoring and reviewing the line of treatment with better antenatal care, early recognition and hospital treatment of patients can decrease the incidence rate of severe preeclampsia and eclampsia.

\section{KEYWORDS}

Severe Preeclampsia, Eclampsia, Low Birth Weight

\section{INTRODUCTION:}

Preeclampsia and eclampsia are a multisystem disorder occurring during pregnancy, complicating $3-8 \%$ of pregnancies accounting 10 $15 \%$ of maternal and neonatal mortality and morbidity. It was found that $3-5 \%$ of first pregnancies and $1 \%$ of subsequent pregnancies are complicated by preeclampsia. WHO estimated that approximately 60,000 women die each year from pre-eclampsia world-wide. ${ }^{(1-4)}$

Pre-eclampsia and eclampsia account for $24 \%$ of all maternal deaths in India, mainly attributed to complications like accidental haemorrhage, disseminated intravascular coagulation, pulmonary oedema, cardiac failure, HELLP syndrome, renal failure, adult respiratory distress syndrome and cerebral haemorrhage. In India, maternal mortality and morbidity from eclampsia is very high. The figure ranges from $8-14 \%$. The perinatal mortality ranges from $14.6 \%$ to $47.4 \%{ }^{(1-4)}$ It is a pregnancy specific syndrome with its onset being post 20 weeks period of gestation. Preeclampsia is defined as new onset of elevated blood pressure and proteinuria $(\mathrm{BP}>/=140 / 90$ and $>/=0.3 \mathrm{gm}$ protein in 24 hours urine specimen) after 20 weeks of gestation in a previously normotensive woman. It is considered severe if blood pressure and proteinuria are increased substantially $(\mathrm{BP}>/=160 / 110$ and $>5 \mathrm{gm}$ protein in 24 hours urine specimen) or symptoms of end organ damage like thrombocytopenia, altered liver function, oliguria, cerebral or visual disturbances, pulmonary oedema and foetal growth restriction are present.

Eclampsia is defined as the new onset of generalized tonic clonic seizure in a woman with severe preeclampsia. Seizures most commonly occur in the postnatal period in $44 \%$ cases, antenatally in $38 \%$ and in the intrapartum period in $18 \%{ }^{(4-6)}$

An imposing number of mechanisms have been proposed to explain the cause of preeclampsia and eclampsia which mainly includes theory of abnormal trophoblastic invasion, immunological maladaptive tolerance theory, genetic factors, maternal maladaptive tolerance to cardiovascular or inflammatory changes. Gradients for management of Preeclampsia depends upon its severity. Antepartum diagnosis of eclampsia and severe preeclampsia are based on the defined criteria as per guidelines. The challenge is in management of Severe preeclampsia and it progressing to Eclampsia is one of the most dreaded nightmares for an Obstetrician. The basic management objectives mainly include termination of pregnancy with least possible trauma to mother and foetus. As preeclampsia is a progressive disorder, in some circumstances, delivery is essential to halt the further progression of the disease to the benefit of mother and foetus. Besides the need for preterm delivery, in $2 / 3^{\text {rd }}$ patients late preterm deliveries mainly contribute a major chunk of burden for preterm care and adverse neonatal outcomes compared to early preterm cases. The identification of prominent impending signs and the prime objective being to forestall generalized tonic-clonic convulsions, prevent intracranial haemorrhage and serious damage to other vital organs, and to deliver a healthy neonate. Several subsequent reports also highlighted other associated complications such as stroke, pulmonary embolism, pulmonary oedema, aspiration pneumonia, placental abruption, cardiopulmonary arrest, comatose state, etc. One of the most important clinical questions for successful management is precise knowledge of foetal age. Life expectancy of women who developed preterm preeclampsia, requiring delivery at $<37$ weeks, is reduced on an average by 10 years. Risk of prematurity is inevitable in most of the patients presenting with preeclampsia and eclampsia. The conservative or expectant management with the aim of improving neonatal outcome without compromising maternal safety includes daily and usually more frequent inpatient monitoring of the mother and her foetus. Though this approach is reasonable but at cost of the survival of both mother and foetus. Besides treatment approaches, in developing countries, availability of adequate and advanced facilities for prompt and intensive maternal and foetal surveillance, neonatal intensive care facilities are one of the major challenges still to be resolved. Ignorance by patients is one of the factors, the health care personnel deal with among low socioeconomic class irrespective of adequate counselling on out- patient basis. ${ }^{(1-4,6)}$

\section{AIMS AND OBJECTIVES:}

The aim is to study severe preeclampsia and eclampsia and associated maternal and foetal outcomes at a rural tertiary health care centre.

\section{MATERIALSAND METHODS:}

This is a prospective cohort study conducted at Sri Adichunchanagiri Institute of Health Sciences and Research Centre, B.G Nagara, Karnataka from July 2018 to December 2019. Patients included in the study were as per inclusion and exclusion criteria. Patients with severe preeclampsia and eclampsia were included by thorough history taking and data was entered in Microsoft Excel and outcomes were analysed using Epi Info software.

\section{RESULTS:}

Out of 3068 deliveries conducted, 157 cases were diagnosed with severe preeclampsia and eclampsia. Incidence of severe preeclampsia 
being $4.7 \%(n=146)$, and that of eclampsia $(n=11,0.3 \%)$. Majority belonged to age group $21-25 y$ years $(47.1 \%)$ of which 71 had severe preeclampsia (45.2\%) and 3 cases (1.9\%) had eclampsia. But however, most eclampsia cases were noted in age group between 26-30 years $(\mathrm{n}=6)$ which accounted $3.8 \%$ of the total cases of eclampsia. Out of total eclampsia cases noted, $(n=6) 54.5 \%$ belonged to age group of 26 30 years. ${ }^{\text {(table. } 1-2)}$

Table no: 1 Antenatal care for preeclampsia and eclampsia

\begin{tabular}{|l|l|l|}
\hline Antenatal Care & Severe Preeclampsia & Eclampsia \\
\hline Unbooked/Referred & $43(27.3)$ & $11(7.0 \%)$ \\
\hline Booked & $103(65.6 \%)$ & - \\
\hline
\end{tabular}

Table no. 2: Age distribution in preeclampsia and Eclampsia

\begin{tabular}{|l|l|l|}
\hline Age & Severe Preeclampsia & Eclampsia \\
\hline $\mathbf{1 6 - 2 0}$ year & $12(7.6 \%)$ & 0 \\
\hline $\mathbf{2 1 - 2 5}$ year & $71(45.2 \%)$ & $3(1.9 \%)$ \\
\hline $\mathbf{2 6 - 3 0}$ year & $54(34.3 \%)$ & $6(3.8 \%)$ \\
\hline $\mathbf{3 1 - 3 5}$ year & $9(5.7 \%)$ & $2(1.2 \%)$ \\
\hline Total $(\mathbf{n}=\mathbf{1 5 7})$ & 146 & 11 \\
\hline
\end{tabular}

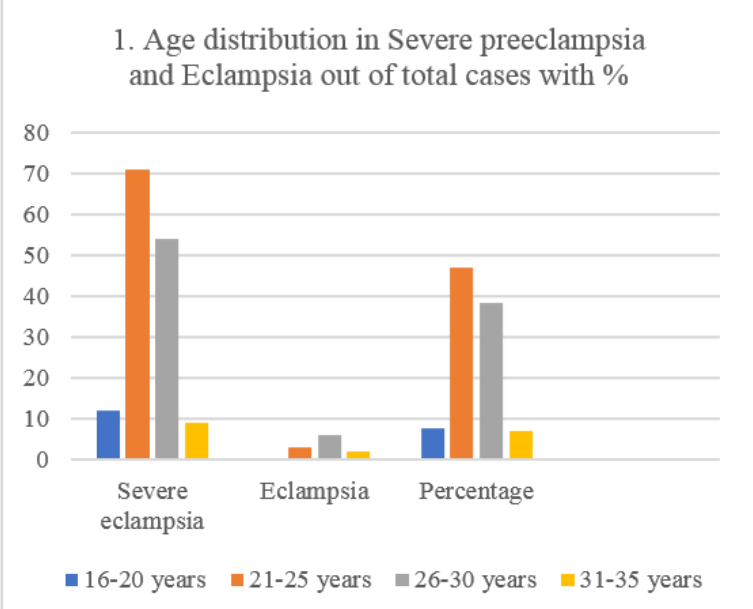

Out of the total cases, primigravida accounted $(\mathrm{n}=90) 57.3 \%$, of which $51.5 \%$ were severe preeclamptic, while $5.7 \%(\mathrm{n}=9)$ were eclamptic. Multigravidas accounted for $42.6 \%(n=67)$ of total cases, of which eclampsia cases summed up to $2.9 \%(\mathrm{n}=2)$ and preeclampsia cases accounted $97.01 \%$ of the total cases, patients who delivered before 32 weeks accounted $21.6 \%(\mathrm{n}=34)$ of which preeclampsia was noted in $97.05 \%(\mathrm{n}=33)$ while 1 case of eclampsia delivered at 28 weeks $(\mathrm{n}=1)$ $2.9 \%$, while between $32-34$ weeks were $29.9 \%(n=47)$. From $34-$ $36(+6)$ week period of gestation, deliveries noted were amounting $17.8 \%(\mathrm{n}=28)$ of the total cases, of which $92.8 \%$ were preeclamptic while $7.14 \%$ accounted for eclampsia cases $(n=2)$ (table:-3-4) $^{\text {(t) }}$

\begin{tabular}{|l|l|l|}
\hline Table No. 3: Parity Distribution \\
\hline Parity & Severe preeclampsia & Eclampsia \\
\hline Primigravida & $81(51.5 \%)$ & $9(5.7 \%)$ \\
\hline Multigravida & $65(41.4 \%)$ & $2(1.2 \%)$ \\
\hline
\end{tabular}

Table No. 4: Gestational Age Distribution in Preeclampsia and Eclampsia

\begin{tabular}{|l|l|l|}
\hline Gestational age (weeks) & Preeclampsia & Eclampsia \\
\hline$>\mathbf{3 7}$ weeks & $46(31.5 \%)$ & $2(18.1 \%)$ \\
\hline
\end{tabular}

Among all the eclampsia cases noted, antepartum onset was noted in $54.5 \%(n=6)$, while postpartum onset was noted in $36.3 \%$ cases. Only 1 case had eclamptic episode intrapartum accounting 9.09\%. (graph.2)

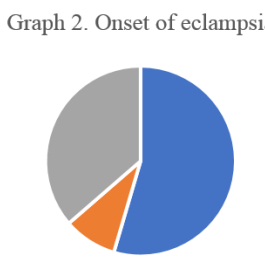

- Antepartum - Intrapartum = Postpartum

Most common sign and symptom noted was high blood pressure and associated oedema feet with blurring of vision. ${ }^{\text {(able: } 5 \text {; graph.3) }}$
Table No. 5 Symptoms and Signs in Preeclampsia and

Eclampsia

\begin{tabular}{|l|l|}
\hline Symptoms/Signs & Cases \\
\hline Convulsions & $11(7 \%)$ \\
\hline Headache & $\mathbf{8 4}(53.5 \%)$ \\
\hline Vomiting & $74(47.1 \%)$ \\
\hline Blurring of Vision & $\mathbf{8 2 ( 5 2 . 2 \% )}$ \\
\hline Epigastric pain & 0 \\
\hline Oedema feet & $112(71.3 \%)$ \\
\hline Oliguria & 0 \\
\hline Generalized oedema/ascites & 0 \\
\hline High Blood pressure & $157(100 \%)$ \\
\hline
\end{tabular}

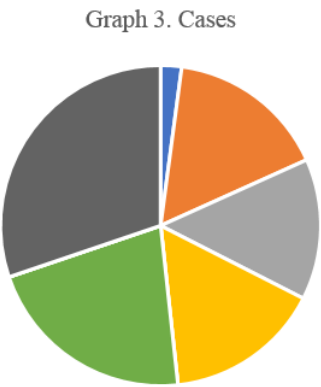

$\begin{array}{lll}\text { - Convulsions } & \text { " Headache } & \text { "Vomitting } \\ \text { = Blurring of Vision } & \text { " Epigastric pain } & \text { - Oedema Feet } \\ \text { - Oliguria } & \text { - Generalized Oedema/Ascites } & \text { - High Blood Pressure }\end{array}$

Out of 146 preeclampsia cases, Caesarean section was undertaken in $36.9 \%(n=58)$ of preeclamptic patients, among eclampsia cases, 6 cases underwent caesarean delivery and 1 case underwent vacuum assisted vaginal delivery while 4 cases underwent delivery through normal vaginal route. A total of $69.4 \%$ preterm deliveries $(n=109)$ were observed while term deliveries accounted for $27.3 \%(n=43)$ of the total cases. ${ }^{\text {(graph.4) }}$

Graph 4. Mode of Delivery

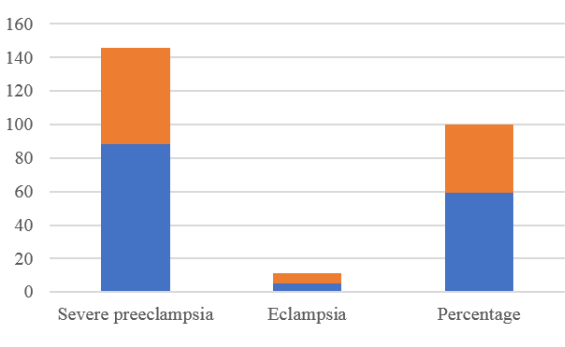

- Vaginal Delivery $\quad$ Emergency LSCS

\begin{tabular}{|l|l|l|}
\hline Table No 6: Indications for Caesarean Delivery \\
\hline $\begin{array}{l}\text { Indications of Caesarean } \\
\text { Section }\end{array}$ & Severe Preeclampsia & Eclampsia \\
\hline Foetal distress & $12(18.7 \%)$ & $2(3.12 \%)$ \\
\hline Failed induction & $9(14.0 \%)$ & $2(3.1 \%)$ \\
\hline Previous LSCS & $8(12.5 \%)$ & - \\
\hline Breech & $2(3.1 \%)$ & $1(1.5 \%)$ \\
\hline IUGR & $19(29.6 \%)$ & - \\
\hline Non-reactive NST & $8(12.5 \%)$ & $1(1.5 \%)$ \\
\hline Total: & $58(90.6 \%)$ & $6(9.3 \%)$ \\
\hline
\end{tabular}

Among indications for caesarean deliveries, IUGR was the most common indication $(\mathrm{n}=19,32.7 \%)$ among preeclampsia group followed by foetal distress in $20.6 \%(n=12)$. Overall IUGR being the most common indication, comprised a total of 19 patient $(29.6 \%)$ in preeclampsia group, while foetal distress being $21.8 \%(\mathrm{n}=14)$. ${ }^{\text {(table: } 6)}$

Most common maternal complication was HELLP syndrome followed by post-partum haemorrhage and abruptio placenta. No maternal mortality was recorded during the period in which the study was conducted secondary to preeclampsia and eclampsia as a direct cause or immediate cause of death. Out of 143 cases (excluded IUD and Stillborn), $26.5 \%$ had respiratory distress and required NICU care. ${ }^{(\text {table } 6-7 ; \text {; graph. } .5)}$ 


\begin{tabular}{|l|l|l|}
\hline \multicolumn{3}{|l|}{ Table No. 7: APGAR score } \\
\hline APGAR Score & Severe Preeclampsia & Eclampsia \\
\hline APGAR 7-10 & $119(83.2 \%)$ & $7(4.8 \%)$ \\
\hline APGAR 5-6 & $17(11.8 \%)$ & - \\
\hline APGAR 0-3 & - & - \\
\hline Total Patients: 143 & & \\
\hline
\end{tabular}

Graph 5. Matemal complications

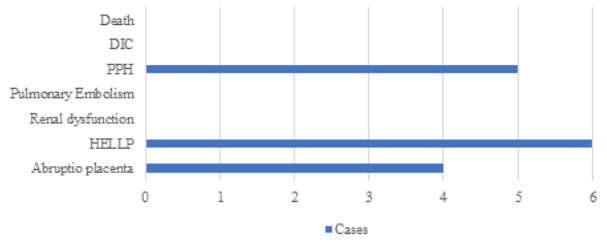

Neonatal death among eclampsia group was noted in one case $(0.6 \%)$ and 4 cases died in preeclampsia group (2.5\%). IUD was noted in $7.6 \%$ (preeclampsia group: $(\mathrm{n}=9)$ ) $6.16 \%$ while eclampsia group $(\mathrm{n}=3)$ $27.2 \%)$. Overall stillborn were noted in $1.2 \%$ cases $(n=2)$. Neonatal death among eclampsia group was noted in one case $(0.6 \%)$ and 4 cases died in preeclampsia group $(2.5 \%)$.

Neonates with APGAR 7-10 accounted $83.2 \%$ while $11.8 \%$ were having APGAR between 5-6 among the preeclampsia group. APGAR between $7-10$ was noted among eclampsia group in $4.4 \%(n=7)$. LBW in $75.15 \%$ of which $69.4 \%(n=109)$ belonged to preeclampsia group while $5.7 \%(n=9)$ belonged to eclampsia group. Only $24.8 \%(n=39)$ cases had birth weight between $2.6-3.5 \mathrm{~kg}$, which means only 2 neonates $(5.1 \%)$ among the eclampsia group had birth weight between 2.6-3.5kg. Out of 143 cases (excluded IUD and Stillborn), 26.5\% had respiratory distress and required NICU care. The causes for perinatal morbidity included prematurity mainly accounting 76 neonates $(53.1 \%)$, neonatal hyperbilirubinemia was noted in $2.7 \%$ cases $(n=4)$, while Meconium aspiration was noted in $4.19 \%(n=6)$. Among maternal complications, 6 cases were diagnosed with HELLP syndrome $(3.8 \%)$, PPH in $3.18 \%(n=5)$, while 2 cases required ICU admission $(1.2 \%)$. ${ }_{\text {(tablec-7-8; ; graph.5-6) }}$

\begin{tabular}{|c|c|c|}
\hline \multicolumn{3}{|c|}{$\begin{array}{l}\text { Table No. 8: Birth weight of babies in Preeclamptic and } \\
\text { Eclamptic Patients }\end{array}$} \\
\hline Birth Weight & Severe Preeclampsia & Eclampsia \\
\hline$<1.5 \mathrm{~kg}$ & 39 & - \\
\hline $1.6-2 \mathrm{~kg}$ & 49 & 5 \\
\hline $2.1-2.5 \mathrm{~kg}$ & 21 & 4 \\
\hline $2.6-3 \mathrm{~kg}$ & 16 & 1 \\
\hline$>3.1 \mathrm{~kg}$ & 21 & 1 \\
\hline Total & 146 & 11 \\
\hline
\end{tabular}

Graph 6. Perinatal Morbidity

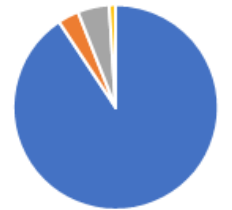

$$
\begin{aligned}
& \text { - Prematurity } \\
& \text { - Neonatal Hyperbilirubinaemia } \\
& \text { - Meconium Aspiration Syndrome } \\
& \text { - Respiratory Distress }
\end{aligned}
$$

A total of 136 patients received Pritchard's Regimen (86.6\%). All patients received Antihypertensives and among booked cases a total of $59.2 \%(\mathrm{n}=93)$ were started on Pritchard's regimen. Among booked cases of severe preeclampsia, 10 (6.3\%) patients received Prophylactic Inj. Magnesium Sulphate and were responding to Antihypertensives alone. Among the remaining 11 unbooked cases, only $3(1.9 \%)$ preeclamptic were given prophylactic dose of $\mathrm{MgSO} 4$ outside and were continued on Antihypertensives at our hospital while rest 5.09\% $(n=8)$ received their initial first doses of prophylactic Magnesium sulphate dose at our hospital along with antihypertensives ${ }^{\text {(table:s) }}$

Table No.9: Injection Magnesium Sulphate (Pritchard's Regimen) at our Hospital

\begin{tabular}{|l|l|l|}
\hline Treatment & $\begin{array}{c}\text { Severe } \\
\text { Preeclampsia }\end{array}$ & Eclampsia \\
\hline
\end{tabular}

\begin{tabular}{|l|l|l|}
\hline Pritchard's Regimen $93(59.2 \%)$ & {$[11(7 \%)$ patients referred from }
\end{tabular}

\begin{tabular}{|l|l|l|} 
(In-patient) & $\begin{array}{l}\text { outside to our hospital, 6 } \\
\text { patients were given loading } \\
\text { dose and 5 patients received } \\
\text { loading dose at our hospital } \\
\text { and all patients received } \\
\text { maintenance dose] }\end{array}$ \\
\hline $\begin{array}{l}\text { Pritchard's } \\
\text { Regimen- } \\
\text { unbooked/referred } \\
\text { to our hospital) }\end{array}$ & $32(20.3 \%)$ & \\
\hline
\end{tabular}

Total: 136(86.6\%) A total of $21(13.3 \%)$ severe preeclampsia cases responded well to only antihypertensives and of these 13 were simultaneously given prophylactic loading dose of Inj. MgSO4 without maintenance dose.

\section{DISCUSSION:}

The global distribution of the incidence of all deliveries for preeclampsia and eclampsia is estimated to be $2.16 \%$ and $0.28 \%$ respectively. Data on the incidence of Hypertensive disorders pregnancy are scarce, based on a published systematic review, where just 74 studies from 40 countries reported the incidence of preeclampsia and eclampsia, only seven of these with data on national coverage. The risk of foetal and neonatal deaths, as well as preterm birth and admission to NICU, was, in general, similarly increased in both conditions, albeit slightly higher in eclampsia. ${ }^{(5)}$ The incidence of pre-eclampsia in our setting is similar to those in other studies conducted by Hernandez et al being $4.7 \%(n=146)$, and that of eclampsia $(n=11,0.3 \%)$. Advanced maternal age has been found to be an independent risk factor for pre-eclampsia, while in this study most of the cases were in the age group 26-30, which is similar to study conducted by Abalos et al and Seyom et al. ${ }^{(8-9)}$ Prevalence of preeclampsia and eclampsia in primigravida of the total cases was 90 $(57.3 \%)$, preeclampsia being $90 \%(\mathrm{n}=81)$ and eclampsia being $10 \%$ $(n=9)$ while multigravidas accounted for $42.6 \%$ in our study which was similar most of the studies conducted.

There is also an increased risk of severe pre-eclampsia and eclampsia in unregistered women. This indicates that women who are registered have pre-eclampsia diagnosed earlier and treated and could also indicate that women with pre-eclampsia and eclampsia were being referred to our institution for further management as it being a Rural tertiary care centre..$^{(7)}$

Out of 157 patients, 11 patients were referred for having convulsions as the chief complaint. High BP readings was the commonest sign of presentation in all patients of severe pre-eclampsia and eclampsia altogether followed by oedema feet and headache. None of the patients with severe pre-eclampsia had convulsions and none of the eclampsia cases had further repeat episode of convulsions after being referred to under our care. Intrauterine deaths were mainly seen among unregistered patient. ${ }^{(1-3)}$

The incidence of perinatal mortality is lower in our study, with neonatal deaths being $3.4 \%$ while in study conducted by Aabidha et al it was $4.3 \%$ and also it was comparatively lower than all the other studies. Neonatal outcomes were similar to study conducted by Saxena $\mathrm{N}$ et al and Aabidha et al and Shaikh $\mathrm{S}$ et al. In our study the percentage of neonatal death, intrauterine foetal death and stillbirth were less compared to other studies. ${ }^{(1-4)}$

\section{CONCLUSION:}

There is a high frequency of pre-eclampsia in our setting and the consequences of pre-eclampsia for neonatal mortality and morbidity outcome are alarmingly high.

There is need for patients' education in recognizing the warning symptoms of severe pre-eclampsia before the intrauterine demise of foetus occurs or mother develops one of the grave complications, this is mainly down to lack of regular antenatal check-ups, associated complications, lack of awareness regarding significance of symptoms and signs.

The importance of continued efforts in monitoring and reviewing the line of treatment with better antenatal care, early recognition and hospital treatment of patients can decrease the incidence rate of severe preeclampsia and eclampsia.

Abbreviations: LBW: Low Birth Weight; HELLP: Hemolysis, 
Elevated liver enzymes, low platelet; ICU: intensive care unit; IUGR: Intrauterine Growth Restriciton; $\mathrm{MGSO}_{4}$ : magnesium sulphate; NICU: Neonatal Intensive care Unit; PPH: Post Partum Hemorrhage; IUD: Intrauterine Death

\section{REFERENCES:}

Aabidha PM, Cherian AG, Paul E, Helan J. Maternal and fetal outcome in pre-eclampsia in a secondary care hospital in South India. J Fam Med Primary Care 2015;4:257-60

2. B. M. Sibai, S. N. Caritis, E. Thom et al., "Prevention of preeclampsia with low-dose aspirin in healthy, nulliparous pregnant women. The National Institute of Child Health and Human Development Network of Maternal-Fetal Medicine Units," The New England Journal of Medicine, vol. 329, no. 17,pp. 1213-1218,1993.

3. B. M. Sibai, "Diagnosis and management of gestational hypertension and preeclampsia," Obstetrics and Gynecology, vol. 102, no. 1, pp. 181-192,2003.

Saxena N, Bava AM, Nandanwar Y. Maternal and perinatal outcome in severe preeclampsia and eclampsia. Int J Reprod Contracept Obstet Gynecol 2016;5: 2171-6.

5. Ness R, Robert J American Journal of Obstetrics and Gynaecology 1996 vol. 175 (5) pp. 1365-1370

6. Backes CH, Markham K, Moorehead P, Cordero L, Nankervis CA, Giannone PJ. Maternal preeclampsia and neonatal outcomes. J Pregnancy.2011;2011:214365

7. Ngwenya S. Severe preeclampsia and eclampsia: incidence, complications and perinatal . outcomes at a low-resource setting, Mpilo Central Hospital, Bulawayo, Zimbabwe. Int

8. Seyom E, Abera m, Tesfaye M, Fentahun N. Maternal and fetal outcome of pregnancy related hypertension in Mettu Karl Referral Hospital Ethiopia. J Ovarian Res. 2015;8:10

9. Harnandez-Diaz S, Toh S, Cnattinggius S. Risk of preeclampsia in first and subsequent pregnancies: prospective cohort study. BMJ. 2009;338:b2255 